\title{
ERRATA
}

\section{VOLUME 3}

Page 134, line 32. For the second occurrence of " (IV) ", read " (V) ".

\section{VOLUME 6}

Page 19, line 31. For " to to ", read " to" .

Page 93. In each of the last five lines on this page, replace the last occurrence of $=$ by $\neq$.

Page 188, second column, line 19 from the bottom and line 6 from the bottom. For 31 , read 30 .

\section{VOLUME 7}

Page 103, line 7 from the bottom. For « Kuratowski », read " Kuratowskiego ".

Pages 111, 112. See the author's footnote on page 9 of volume 14 .

\section{VOLUME 9}

Page 104, line 25. For « Tarksi's ", read "Tarski's ».

VOLUME 10

Page 12, line 7. For « moduc ", read « modus".

\section{VOLUME 11}

Page 115. In the second line of XXVI, for the last -3 , read $\supset$.

Page 116, line 23. For $\left(\alpha_{1}\right)\left(\alpha_{2}\right)$ B $\ldots\left(\alpha_{m}\right)$, read $\left(\alpha_{1}\right)\left(\alpha_{2}\right) \ldots\left(\alpha_{m}\right)$ B.

Page 118, footnote 7, line 3. For $A_{n}, \operatorname{read} A_{i}$.

\section{VOLUME 13}

Page 133. In $\nmid 741$, change $u$ to $n$, and insert a bar over $\iota y$.

Page 168, lines 16-17. For "Adjukiewicz ", read « Ajdukiewicz ".

Page 176, line 7. For "dan", read "dans".

Page 225, line 23. For " mathematiche", read " matematiche».

Page 225, line 34. For \& does ", read " goes".

Page 233, line 6 from the bottom. Delete the first comma in the line.

\section{VOLUME 14}

Page 56. Supply the page number, « $56 "$, in the upper left corner.

Page 63, line 21. For "SMielew ", read " Szmielew 》.

Page 71, line 12 from the bottom. For "sciences $"$, read « science ".

Page 70, line 36. For a esprimibiltà ", read « esprimibilità"

Page 114. In [8], for « Congrés ", read "Congrès".

Page 116, line 5 from the bottom. For $P T Q_{1}$ read $P R Q_{1}$.

Page 118, line 2. For $B_{1} U_{2}^{*}$, read $B_{1}^{*} U_{2}^{*}$.

Page 118, line 4. For $p+1 \geqq i$, read $i \geqq p+1$.

Page 118, line 3 from the bottom. For $T$ baab, read $R$ baab.

Page 139, line 13. For " basés ", read « basées".

Page 140, line 16. For " paraissantes ", read « paraissant ".

Page 143, line 2 from the bottom; page 144, lines 2, 4, 7. For XIV (62), XIV (63), XIV (64),

Page 163, line 5. For $\Gamma_{i}$, read $\Gamma_{1}$. [read respectively XIV 62, XIV 63, XIV 64.

Page 163, line 7. For $\Gamma_{1}$, read $\Gamma_{i}$.

Page 165, line 24. For $\left(\Lambda, E_{1}, E_{2}\right)$, read $\left(\Lambda, E_{1}^{\prime}, E_{2}^{\prime}\right)$; and in the latter part of the line, for Page 165, line 27. For « $\Lambda, E_{1}, E_{2} »$, read « $\Lambda, E_{1}^{\prime}, E_{2}^{\prime} »$. $\left[E_{1}\right.$, read $E_{i}^{\prime}$. Page 177. In 2.41, for $\iota^{\mathrm{n}}$, read $\iota^{\mathrm{m}}$.

Page 189, line 18. For " relation numbers ", read «relation-numbers".

Page 193, line 21. For " Structure ", read " Structures ".

Page 197, line 23 from the bottom. After " of ", insert " the ".

Page 205, line 6 from the bottom. For « $A N D$ 'S ", read " $A N D$ 's ".

Page 208, line 20. For " methodes ", read " méthodes "; and for « de », read « du".

Page 208, line 23. For « deductive ", read « déductive». 